\title{
Hydrodynamics of Biomass Gasification in a Dual Chamber Circulating Fluidized Bed Reactor
}

\author{
Haifa Wahyu ${ }^{1}$, Imam Djunaedi ${ }^{2}$, M. Affendi ${ }^{2}$ and M. T. Sugiyatno ${ }^{2}$ \\ ${ }^{1}$ Research Centre for Physics, Indonesian Institute of Sciences - Lembaga IImu Pengetahuan Indonesia, Kompleks LIPI, Jln. Sangkuriang \\ 21/154D, Bandung 40135 - Indonesia \\ ${ }^{2}$ Research Centre for Electric Power and Mechatronics, Indonesian Institute of Sciences - Lembaga IImu Pengetahuan Indonesia, Kompleks \\ LIPI, JIn. Sangkuriang 21/154D, Bandung 40135 - Indonesia
}

\begin{abstract}
This paper presents work on hydrodynamics of several types of biomass mixture in a dual chamber circulating fluidized bed. In designing the CFBreactornecessary to know the distribution of solid particles radially and axially influenced by fluidizing gas velocity, particle size, solid circulation flux, reactor diameter and height of the reactor. These factors will affect pressure drop along the riser of the reaction chamber. Pressure drop is an important factor in the study of hydrodynamics of particle flow. The pressure drop was measured using mathematical model compared to experimental results done on a cold mode. Since it was found that both results were consistent which means that the model can be used to predict the operating parameters of CFB design.
\end{abstract}

\section{Introduction}

Flow hydrodynamics is an important aspect in designing circulating fluidized bed systems. Knowledge on the particle distribution along the reactor column will help determining the operational parameters of the reactors especially the pressure loss. Modeling of the flow structure in circulating fluidized bed has been studied by de Diego et al (1995) [1]. They used a mixture of sand and coal to study the particle distribution at axial position along the riser. They observed that there were dense zone and dilute zone. In the dilute region, the upward and downward particle fluxes decreased as the height of the riser increased. This was due to the net transfer of solid fluxes from the core to the annulus. Based on this observation they developed a mathematical model of a core-annulus flow structure in the dilute region. At an earlier stage, Hannes (1996) [2] applied bubble fraction in modeling the circulating fluidized bed for the combustion of coal and sand. By studying the bubble fraction and solid concentration along the riser, distribution of solid particles along the riser can be determined.Studies on hydrodynamics of a biomass gasifier semi dual fluidized bed in a cold-rig was done by Ngo et al (2013) [3]. A semi-dual fluidized bed is a novel design of dual fluidized bed where there was an internal mixing of solid particles between the riser and the gasifier. It was developed to enhance the heat and mass transfer in the system. This was shown by $17 \%$ of back mixing obtained during the experiment. The use of gas injection and liftover in a dual fluidized bed was studied by Loffler et al (2003) [4] in an 8 MW gasifier.
The purpose is to determine the effect of secondary gas injection in the fluid dynamics of the system. It was found that the gas injection the riser has the effect on the gas flowrate.

The study used mathematical model and experiments.Kaiser et al (2003) [5] in the Part II of the studies of the hydrodynamics of a dual fluidized bed gasifier determined the solids circulation and the distribution of the solid hold up of a CFB gasification system under different conditions. The behavior of the system was then analyzed using solid concentration and variations of geometry. The concept of hydrodynamics was also applied for catalytic studies for the treatment of wastes as shown by San Jose et al (2009) [6]. The aim was to achieve stable operating conditions by differentiating the geometric factor of the conical contactor and of the contactor-particle system. Further investigation of solids circulation in a circulating fluidized bed was done by Lim et al (2012) [7] where they tried to understand how operating parameters influence solids circulation. Solids circulation affects the heat transfer that sustained the reactions in the systems. Fluidization properties of torrefied biomass were also studied by Rousset et al (2012) [8] to predict the behavior of amorphous and multi-dimensional particles of the biomass. The indicator was bed pressure drop. Continuous radial profiles of velocities and solids holdup of sewage sludge gasification was studied in threedimensional model of a circulating fluidized bed gasifier by Petersen et al (2005) [9]. They studied the number of feeding points for different size of gasifiers. It was found out that better mixing was obtained if the number of 
feeding points was larger and the column diameter was wider as well.Gungor et al (2013) [10] used particle based approach and two dimensional numerical computation to predict the hydrodynamics of biomass gasifier. The model was used to simulate the radial and axialprofiles of the bed temperature and the volumetric fraction of $\mathrm{H}_{2}, \mathrm{CO}, \mathrm{CO}_{2}$ and $\mathrm{CH}_{4}$ as well as tar concentration. Other researchers who also involved in using hydrodynamics concept to study fluidized bed reactor and circulating fluidized for gasification were among others Sadak et al (2002) [11], Gungor (2008) [12], Svoboda et al (2009) [13], Kersten et al (2009) [14], Kaushal et al (2008) [15], Zhang et al (2012) [16], Fushimi et al (2011) [17], Charitos et al (2010) [18], and Bi et al (2010) [19]. Most of the researchers work used coal, sand, or biomass alone as the fluidized material. In this work, we used several types of biomass in a mixture of sand in a dual chamber circulating fluidized bed. The purpose is to determine the flow behavior or the hydrodynamics of different characteristics of biomass at a certain operating condition. The experiments were conducted in cold mode.

\section{Theoretical background mathematical formulation}

In designing the CFB reactor necessary to know the distribution of solid particles radially and axially influenced by fluidizing gas velocity, particle size, solid circulation flux, reactor diameter and height of the reactor. By looking at the profile of solids flowin CFB reactors, optimum operating conditions can be determined. Modeling for solids flow structure was built when the solids fluxes out of the area with a high density. To determine the flux of external circulation requires the amount of flux solids on the surface of the solid areas. High area dilute is calculated by taking the balance of the pressure loss of the entire rise rand exponential equations to determine the voidat different heights in this area. To determine the pressure loss of the riser, this work uses mathematical formulation taken from the work of Hannes (1996) [2] and Karmakar et al (2010) [20]. The mathematical formulation is applied to different type of biomass mixture. The results were compared to that of experiments done at the dual chamber circulating fluidized bed rig.

Karmakar [20] defined the riser into three zones, thatare dense where bubbling started, splash zone where the particles started to emerge from the dense bed and transport zone where the particles released from the bed and flow into the exit duct of the chamber. The net voidage in the dense zone is given by the following equation:

$$
\varepsilon_{d, z}=\delta_{b}+\left(1-\delta_{b}\right) \cdot \varepsilon_{m, f}
$$

where $\varepsilon_{d, z}$ is the net voidage, $\delta_{b}$ is the bubbling fraction, and $\varepsilon_{m, f}$ is the voidage at minimum fluidization velocity.

$$
=\left(\frac{1}{1+\frac{1.3\left(0.15+U_{p a}-U_{m f}\right)^{0.35}}{0.26+0.27 \exp \left(-3.3 d_{p}\right)}\left(U_{p a}-U_{m f}\right)^{-0.8}}\right)
$$

$U_{p a}$ is the primary air velocity, and $U_{m f}$ is the minimum fluidization velocity, $d_{p}$ is the solid or the particle diameter.

Solids concentration in a hold up at minimum fluidization velocity was calculated using Archimedes number and sphericity of particles.

$$
\varepsilon_{s . m f}=1-0.586 \emptyset^{-0.72} A r^{-0.029}\left(\frac{\rho_{g}}{\rho_{s}}\right)^{n 0.021}
$$

$\emptyset$ is particle sphericity, Ar number is calculated in the following manner:

$$
A r=\frac{d_{s}^{2} \rho_{g}\left(\rho_{s}-\rho_{g}\right) g}{\mu_{g}^{2}}
$$

where $\rho_{g}$ is the gas density $\left(\mathrm{kg} / \mathrm{m}^{3}\right)$, and $\mu_{g}$ is the gas viscosity $(\mathrm{kg} / \mathrm{ms})$.

Pressure loss is calculated using the following equation where $\Delta P_{d z}$ is the pressure loss $(\mathrm{Pa})$ in dense zone, $\rho_{s}$ is the particle density, $h_{d z}$ is the height of the dense zone and $g$ is gravity.

$$
\Delta P_{d z}=\left(1-\varepsilon_{d z}\right) \rho_{s} h_{d z} g
$$

The behaviour of particles in the splash zone is shown by the bed voidage calculated by taking a decay factor into account. Bed voidage in splash zone equals to

$$
\frac{\varepsilon_{S Z}-\varepsilon}{\varepsilon_{d z}-\varepsilon}=\exp \left[-k\left(h_{s Z}-h_{d z}\right)\right]
$$

$\mathrm{k}$ is the decay factor taken from Karmakar[20]:

$$
k=\frac{C U_{t}}{U_{p a}}
$$

where $\mathrm{C}=10 \mathrm{~m}^{-1}$ is a constant. The pressure loss is the integration of the voidage along the height of the splash zone.

$$
\Delta P_{d z}=\int_{h_{d z}}^{h_{s z}}\left(1-\varepsilon_{s z}\right) \rho_{s} g d h
$$

$\varepsilon_{S Z}$ is the voidage in the splash zone, $h_{d z}$ is the height of the dense bed and $h_{s z}$ is the height of the splash zone.

Bed voidage in transport zone is calculated by incorporating decay factor $a$ and voidage at infinity $\varepsilon_{\infty}$.

$$
\frac{\varepsilon_{t z}-\varepsilon_{\infty}}{\varepsilon_{s Z}-\varepsilon_{\infty}}=\exp \left[-a\left(h_{t z}-h_{s Z}\right)\right]
$$


$a$ is the decay factor of solids fraction and $h_{t z}$ is the height of any solid in transport zone. $U$ is the fluidization velocity and $U_{t}$ is the terminal velocity. $D$ the riser diameter.

$$
a\left(U-U_{t}\right)^{2} D^{0.6}=0.88-420 d_{p}
$$

The infinite voidage in transport section, $\varepsilon_{\infty}$ equals to

where $K_{\infty}$

$$
1-\varepsilon_{\infty}=\frac{K_{\infty}}{\rho_{s}\left(U-U_{t}\right)}
$$

$$
\begin{gathered}
K_{\infty}=\rho_{s} \alpha_{t}\left(U-U_{t}\right) \\
\alpha_{t}=1-\left(1+\frac{f_{s}\left(U-U_{t}\right)^{2}}{2 g D}\right)^{\frac{1}{4.7}}
\end{gathered}
$$

where $\alpha_{t}$ is the velocity head coefficient at cyclone inlet. The coefficient of friction, $f_{s}$, equals to

$$
\frac{f_{s} \rho_{s}}{d_{p}^{2}}\left(\frac{\mu_{g}}{\rho_{g}}\right)^{2.5}=5.17\left[\frac{\rho_{g}\left(U-U_{t}\right) d p}{\mu_{g}}\right]^{-1.5} D^{2}
$$

for

$$
\left[\frac{\rho_{g}\left(U-U_{t}\right) d p}{\mu_{g}}\right] \leq \frac{2.38}{D}
$$

or

$$
\frac{f_{s} \rho_{s}}{d_{p}^{2}}\left(\frac{\mu_{g}}{\rho_{g}}\right)^{2.5}=12.3\left[\frac{\rho_{g}\left(U-U_{t}\right) d p}{\mu_{g}}\right]^{-2.5} D
$$

for

$$
\left[\frac{\rho_{g}\left(U-U_{t}\right) d p}{\mu_{g}}\right] \geq \frac{2.38}{D}
$$

Pressure loss is then calculated using the following equation, where $\Delta P_{d z}$ is the pressure loss in transport zone, $h_{t z}$ is the height of the transport zone, $\varepsilon_{t z}$ is net voidage of the transport zone. $U_{s}$ is the solid velocity in riser.

$$
\begin{array}{r}
\Delta P_{d z}=\int_{h_{s z}}^{h_{t z}}\left(1-\varepsilon_{t z}\right) \rho_{s} g d h \\
+\int_{h_{s z}}^{h_{t z}} f_{s} \frac{U_{s}^{2}}{2} \frac{4}{D}(1 \\
\left.-\varepsilon_{t z}\right) \rho_{s} g d h \\
U_{s}=U-U_{t} \sqrt{\left(1+\frac{f_{s} U_{s}^{2}}{2 g D_{s}}\right) \varepsilon_{t z}^{4.7}}
\end{array}
$$

where

$$
f_{s} \frac{\varepsilon_{t z}^{3}}{1-\varepsilon_{t z}}=0.0126\left[\left(1-\varepsilon_{t z}\right) \frac{U_{t}}{U_{s}}\right]^{-0.979}
$$

for

$$
\frac{U_{t}}{U_{S}}>1.5
$$

or

$$
f_{s} \frac{\varepsilon_{t z}^{3}}{1-\varepsilon_{t z}}=0.0410\left[\left(1-\varepsilon_{t z}\right) \frac{U_{t}}{U_{s}}\right]^{-1.021}
$$

for

$$
\frac{U_{t}}{U_{s}}<1.5
$$

The amount of concentration of solids in the annulus, $\alpha_{\text {cor }}$, of the riser is determined using the following equations. Where $A$ is the area of the riser and $G_{s}$ is the solids flow in the riser.

$$
\begin{gathered}
\bar{\varepsilon}_{s} A=\varepsilon_{\text {s.cor }} \alpha_{c o r} A+\varepsilon_{a n n} \alpha_{a n n} A \\
G_{s} A=u_{\text {s.cor }}\left(1-\varepsilon_{c o r}\right) A \rho_{s} \alpha_{c o r}-u_{a n n}(1 \\
\left.-\varepsilon_{a n n}\right) A \rho_{s} \alpha_{a n n} \\
\varepsilon_{. a n n-}-2 \\
\alpha_{a n n}=\left(1-\alpha_{c o r}\right) \\
\alpha_{\text {cor }}=1-\frac{\varepsilon_{s}-\frac{G_{s}}{\rho_{s . U_{s}}}}{\varepsilon_{\text {s.ann }}\left(1+\frac{w_{s . a n n}}{u_{s . c o r}}\right)}
\end{gathered}
$$

Table 1. Reactor design parameters

\begin{tabular}{|l|l|}
\hline Item & Dimension \\
\hline 1. Gasification Unit & \\
\hline Diameter, m & 0.2 \\
\hline Height, m & 2.250 \\
\hline 2. Combustion Unit & \\
\hline Diameter, m & 0.3 \\
\hline Height, m & 1.750 \\
\hline 3. Operational Parameters & \\
\hline Fluidization velocity, m/s & 0.7 \\
\hline Minimum fluidization velocity, m/s & 0.07 \\
\hline The number of nozzle & 4 \\
\hline Sand bed height, m & 0.02 \\
\hline Material flow input, kg/hour & Max. 33.02 \\
\hline Sand sphericity ( ) & 0.78 \\
\hline Biomass sphericity ( ) & 0.49 \\
\hline 4. Bed zones & \\
\hline Dense zone & $20 \mathrm{~cm}$ height \\
\hline Splash zone & $60 \mathrm{~cm}$ height \\
\hline Transport zone & $2.7 \mathrm{~m}$ height \\
\hline
\end{tabular}




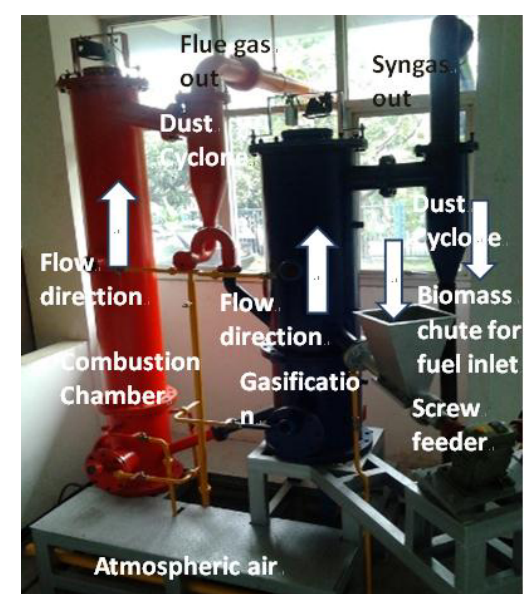

Figure 1. Dual chamber circulating fluidized bed with material flow direction inside the reactor

\section{Methodology}

The aim of this work is to determine the hydrodynamics of a dual chamber circulating fluidized bed with the capacity of $30 \mathrm{~kg} /$ hour for biomass gasification. We employed mathematical equations similar to those in the papers to determine the amount of pressure loss in the system. The results were compared with theexperimental data obtained from the cold test of the equipment on many type of biomass. The equipment is shown in Fig. 1, while design parameters are shown in Table 1.

Pressure loss was measured using manometer tube differences along the riser of the gasification reactor. The following picture shows the manometer attached to the gasifier.

Materials used for this experiment were biomass and quartz sand. The following table shows the list of the materials and their properties.

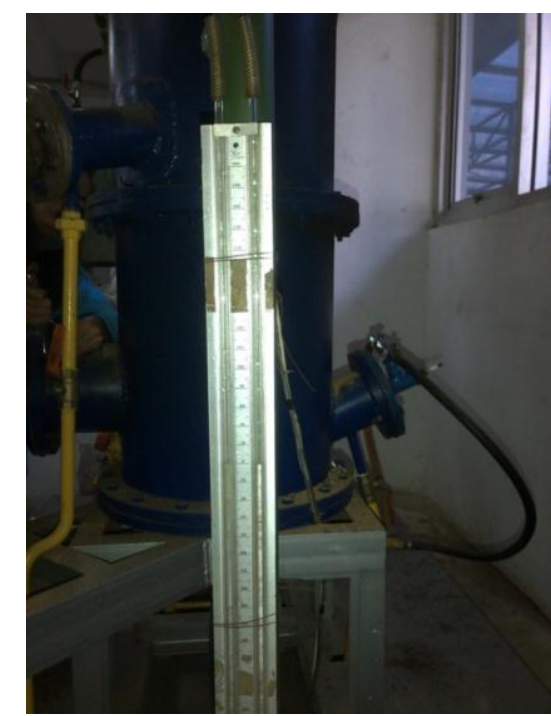

Figure 2. Manometer tube to measure pressure loss

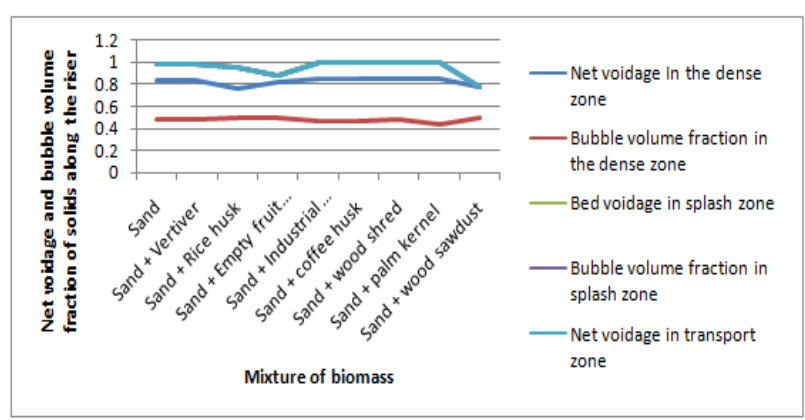

Figure 3. Net voidage of bed in the gasification column

Table 2. Materials used for the experiment on hydrodynamics and their properties

\begin{tabular}{|l|l|l|l|}
\hline Material & $\begin{array}{l}\text { Mixture Density, } \\
\mathrm{kg} / \mathrm{m}^{3}\end{array}$ & Particle diameter, $\mathrm{m}$ & Amount, $\mathrm{kg} / \mathrm{hour}$ \\
\hline Sand & 2650 & 0.002 & 3.9 \\
\hline Sand + Vertiver & 829 & 0.005 & $1.2(50 \%: 50 \%)$ \\
\hline Sand + Rice husk & 389 & 0.005 & $1.2(50 \%: 50 \%)$ \\
\hline Sand + Empty fruit bunch & 80 & 0.004 & $1.2(50 \%: 50 \%)$ \\
\hline Sand + Industrial Sludge & 721 & 0.008 & $1.2(50 \%: 50 \%)$ \\
\hline Sand + coffee husk & 561 & 0.01 & $1.2(50 \%: 50 \%)$ \\
\hline Sand + wood shred & 240 & 0.015 & $1.2(50 \%: 50 \%)$ \\
\hline Sand + palm kernel & 1254 & 0.02 & $1.2(50 \%: 50 \%)$ \\
\hline Sand + wood sawdust & 240 & 0.0001 & $1.2(50 \%: 50 \%)$ \\
\hline
\end{tabular}

\section{Results and discussions}

Using the parameter above, the net voidage of bed in the gasification column can be determined.

Fig. 3 shows net voidage in gasification column for where the results are similar for all types of biomass. The net voidage in the dense zone is almost similar to all types of biomass. Slight differences were observed at the splash and transport zone where the net voidage is lower for biomass with higher density. Dense zone has higher solid concentration, therefore the voidage is less compared to splash and transport zone when applying the same air velocity. Fig. 4 shows fluidization velocity that less that the terminal velocity for each biomass. 


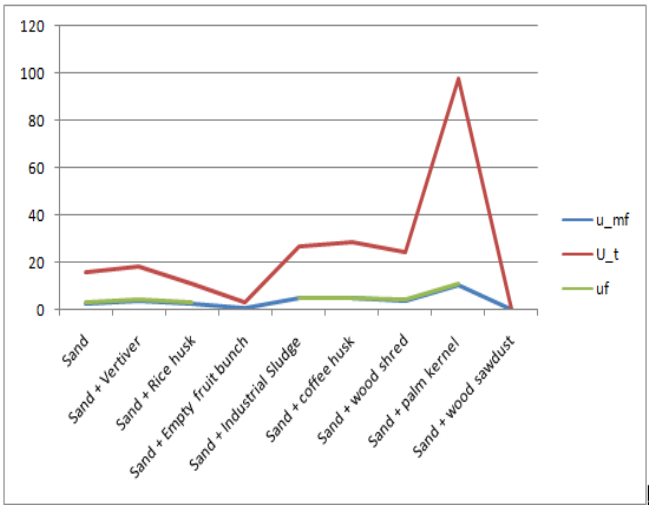

Figure 4. Minimum fluidization velocity, fluidization velocity and terminal velocity

The net voidage has the relationship with the pressure drop in each zone as shown in Fig. 4. Pressure differences is linked to the concentration of solids in each zone.

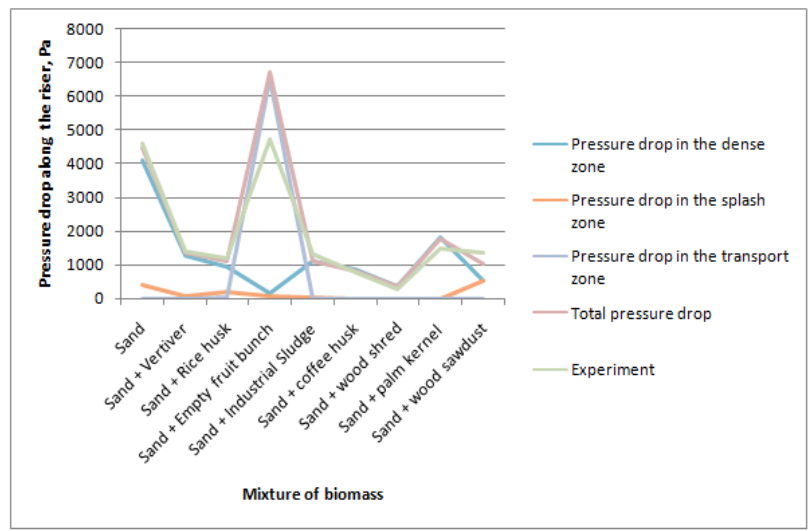

Figure 5. Pressure drop in each zone in gasification column

Pressure drop in each zone is quite consistent with the net voidage of the bed for every biomass. Pressure drop decreases with the increasing of bed height, and thus the fluidization characteristics of biomass particles.However, the results show that the pressure drop from the mathematical calculation is much lower than that of the experimental results. The experiments show that biomass fluidization requires about twice as much as pressure to generate the hydrodynamics of biomass particles in the gasification reactor.

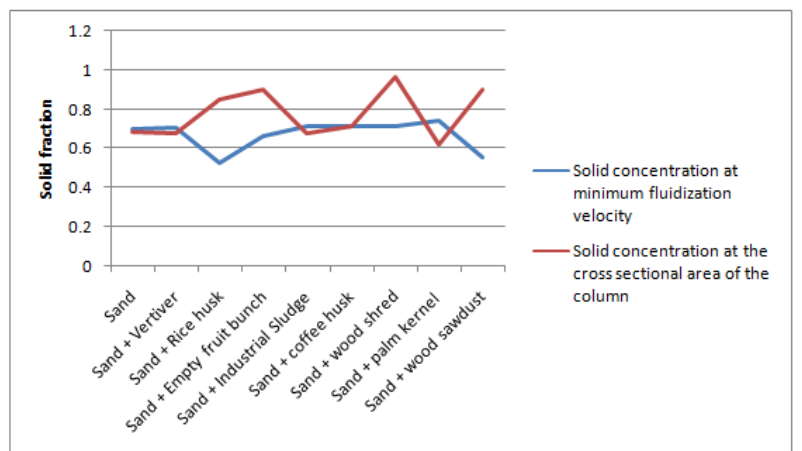

Figure 6. Concentration of solid at minimum fluidization velocity at the core of the reactor column.

Fig. 6 shows the distribution of solids along the reactor column at minimum velocity. $\alpha_{c o r}$ represents the concentration of solids in the middle of the column at the core. At the minimum velocity, most solids are in the core of the cross sectional area of the column. The results are similar for all types of biomass with slightly difference for particle density. If the particle density is high, then the concentration of solids is lower due to the acceleration and decelaration of particles during the fluidization process.

\section{Conclusions}

It was found out that the mathematical model used to determine the pressure loss was consistent with the pressure loss measured during experiments. Differences in density of biomass does not affect solids fraction in the dense zone significantly, but it does affects the solids distribution at the splash and transport zone. This is due to the condition of the particle distribution at this height where more pressure is required to maintain the suspension of solids in this region. Size of biomass does not have the effect, because the size was almost similar due to the requirements of the feeding screw of the biomass. This model can be used to calculate the pressure loss and thus the operating conditions of a dual chamber circulation fluidized bed for mixture of different types of biomass.

\section{Acknowledgements}

The authors would like to thank Research Centre for Physics, Indonesian Institute of Sciences for the opportunity to conduct this research and experiments. We are very grateful with the facilities, including financial, support staff and other infrastructures so that this study can be conducted successfully. We would also like to thank other people who have helped and involved in this work since the beginning.

\section{Nomenclature}

a decay constant, $\mathrm{m}^{-1}$

$A$ the area of the riser

Ar Archimedes number

C constant, $10 \mathrm{~m}^{-1}$

$\mathrm{d}_{\mathrm{p}} \quad$ solid particle diameter $(\mathrm{m})$

$f_{s} \quad$ coefficient of friction,

$g$ gravity $(\mathrm{m} / \mathrm{s})$

$G_{s}$ solids flow in the riser

$h_{d z}$ height of the dense zone (m)

$h_{s z} \quad$ height of the splash zone (m)

$h_{t z} \quad$ height of the transport zone (m)

$\mathrm{k}$ decay factor

$K_{\infty} \quad$ particle elutriation rate constant

$U$ fluidization velocity, $\mathrm{m} / \mathrm{s}$

$U_{p a}$ primary air velocity, $\mathrm{m} / \mathrm{s}$

$U_{m f}$ minimum fluidization velocity, $\mathrm{m} / \mathrm{s}$

$U_{s} \quad$ solid velocity in riser, $\mathrm{m} / \mathrm{s}$

$U_{t} \quad$ terminal velocity, $\mathrm{m} / \mathrm{s}$ 
Greek symbols

$\alpha_{\text {cor }} \quad$ concentration of solids in the annulus

$\alpha_{t} \quad$ velocity head coefficient at cyclone inlet

$\delta_{b}$ bubbling fraction

$\Delta P_{d z} \quad$ pressure loss $(\mathrm{Pa})$ in dense zone

$\Delta P_{S Z}$ pressure loss in splash zone

$\Delta P_{t z}$ pressure loss in transport zone

$\varepsilon_{d, z}$ net voidage in dense zone

$\varepsilon_{S Z}$ net voidage in the splash zone

$\varepsilon_{t z} \quad$ net voidage of the transport zone

$\varepsilon_{m, f}$ the voidage at minimum fluidization velocity

$\varepsilon_{\infty}$. voidage at infinity

$\emptyset \quad$ particlesphericity

$\rho_{g}$ gas density $\left(\mathrm{kg} / \mathrm{m}^{3}\right)$

$\rho_{S}$ particle density $\left(\mathrm{kg} / \mathrm{m}^{3}\right)$

$\mu_{g}$ gas viscosity $(\mathrm{kg} / \mathrm{ms})$

\section{References}

1. L. F. De Diego, P. Gayan, and J. Adanez, (1995) Modelling of the flow structure in circulating fluidized beds, Powder Technology 85, page 19-27.

2. J. P. Hannes, (1996), Mathematical Modelling of Circulating Fluidized Bed Combustion, Thesis Diplom-Ingenieur, Verfahrenstechnik (RWTH Aachen, Duitsland), Duitsland

3. S. I. Ngo,Y. I. Lim, B. H. Song, U. D. Lee, C. W. Yang, Y. T. Choi, and J. H., (2013), Hydrodynamics of cold-rig biomass gasifier using semi-dual fluidized-bed, Powder Technology 234, page 97-106.

4. G. Loffler, S. Kaiser, K. Bosch, and H. Hofbauer (2003), Hydrodynamics of a dual fluidized-bed gasifier - Part I simulation of a riser with gas injection and diffuser, Chemical Engineering Science, 58, page 4197-4293.

5. S. Kaiser, G. Loffler, K. Bosch and H. Hofbauer, , Hydrodynamics of a dual fluidized-bed gasifier Part II: simulation of solid circulation rate, pressure loop and stability, Chemical Engineering Science, 58, pp. 4215-4223, (2003).

6. M. J. San Jose, S. Alvarez, A. Morales, L. B. Lopez, and A. O. de Salazar, Hydrodynamics of catalyst in conical spouted beds, Catalysis Today 147S, pp. S162-S169, (2009).

7. M. T. Lim, S. Pang and J. Nijdam, Investigation of solids circulation in a cold model of a circulating fluidized bed, Powder Technology, 226, pp. 57-67, (2012).
8. P. Rousset, T. Petithuguenin, and A. C. Azevedo, The fluidization behaviour of torrefied biomass in a cold model, Fuel, 102, pp. 256-263, (2012).

9. I. Petersen, and J. Werther, Three-dimensional modeling of a circulating fluidized bed gasifier for sewage sludge, Chemical Engineering Science, 60, pp. $4469-4484$, (2005).

10. A. Gungor and U. Yildirim, Two dimensional numerical computation of a circulating fluidized bed biomass gasifier, Computers and Chemical Engineering, 48, pp. 234-250, (2013).

11. S. S. Sadak, A. E. Ghaly and M. A. Sabbah, Two phase biomass air-steam gasification model for fluidized bed reactors: Part I-model development, Biomass and Bioenergy, 22, pp. 439 - 462, (2002).

12. A. Gungor (), Two-dimensional biomass combustion modeling of CFB, Fuel, 87, pp. 1453-1468, (2008).

13. K. Svoboda, S. Kalisz, F. Miccio, K. Wieczorek, M. Pohořelý, Simplified modeling of circulating flow of solids between a fluidized bed and a vertical pneumatic transport tube reactor connected by orifices, Powder Technology, 192, pp. 65-73, (2009).

14. S. R. A. Kersten, W. Prins, B. van der Drift and W. P. $M$ van Swaaij, Principles of a novel multistage circulating Fluidized bed reactor for biomass gasification, Chemical Engineering Science, 58, pp. $725-731,(2003)$.

15. P. Kaushal, T. Proll, and H. Hofbauer, Model for biomass char combustion in the riser of a dual fluidized bed gasification unit: Part 1 - Model development and sensitivity analysis, Fuel Processing Technology, 89, pp. 651-659, (2008).

16. H. Zhang, R. Xiao, D. Xiao, J. Cho, G. He, S. Shao and J. Zhang, Hydrodynamics of a novel biomass autothermal fast pyrolysis reactor: Solid circulation rate and gas bypassing, Chemical Engineering Journal 181-182, pp. 685-693, (2012).

17. Ch. Fushimi, G. Guan, Y. Nakamura, M. Ishizuka, A. Tsutsumi, S. Matsuda, H. Hatano, and Y. Suzuki, , Hydrodynamic characteristics of a large-scale triplebed combined circulating fluidized bed, Powder Technology, 209, pp. 1-8, (2011).

18. A. Charitos, C. Hawthorne, A. R. Bidwe, L. Korovesis, A. Schuster and G. Scheffknecht, Hydrodynamic analysis of a $10 \mathrm{kWth}$ Calcium Looping Dual Fluidized Bed for post-combustion CO2 capture, Powder Technology, 200, pp. 117-127, (2010).

19. X. T. Bi, and X. Li., High density and high solids flux CFB risers for steam gasification of solids fuels, Fuel Processing Technology, 91, pp. 915-920, (2010).

20. M. K. Karmakar and A. B. Datta, Hydrodynamics of a dual fluidized bed gasifier, Advanced Powder Technology, 21, pp. 521-528, (2010). 